\title{
EEG Correlations during WCST Performance in Female Adolescents with Sexual Abuse-Related Post-Traumatic Stress Disorder
}

\author{
Lucía Ester Rizo-Martínez1, Araceli Sanz-Martin1, Miguel Ángel Guevara1, \\ Marisela Hernández-González ${ }^{1}$, Olga Inozemtseva ${ }^{1}$, Francisco Abelardo Robles-Aguirre ${ }^{2}$ \\ ${ }^{1}$ Instituto de Neurociencias, CUCBA, Universidad de Guadalajara, Guadalajara, México \\ ${ }^{2}$ Centro Universitario del Norte, Universidad de Guadalajara, Colotlán, México \\ Email: aracelisanz@yahoo.com
}

Received 10 March 2015; accepted 6 July 2015; published 9 July 2015

Copyright (C) 2015 by authors and Scientific Research Publishing Inc. This work is licensed under the Creative Commons Attribution International License (CC BY). http://creativecommons.org/licenses/by/4.0/

(c) (i) Open Access

\section{Abstract}

Child sexual abuse (CSA) survivors can present post-traumatic stress disorder (PTSD) and alterations in EEG activity and cognition. The aim of this study was to evaluate EEG correlations in female adolescents with CSA-related PTSD during performance of the Wisconsin Card-Sorting Test (WSCT). Inter- and intrahemispheric EEG correlations (INTERr and INTRAr) of those subjects were calculated at rest and during performance of WCST. On this task, the PTSD group obtained higher scores than the control group for the number of correct responses and failure to maintain set. In the between-groups comparisons, the PTSD group presented a higher INTERr between frontal areas in the gamma and slow bands, as well as a higher correlation in the delta band at Fp1-F3; however, this group presented a lower INTRAr between Fp1-P3 and Fp2-P4 in the theta and alpha1 bands. In the comparison between conditions, the PTSD group presented an increased correlation during execution of the WCST, mainly in the gamma band, while the control group showed a decrease of INTRAr in the slow bands. Results are discussed with respect to the influence of CSArelated PTSD on the development of cognition and functional connectivity in the brain.

\section{Keywords}

Child Sexual Abuse, Post-Traumatic Stress Disorder, EEG Correlation, WCST, Adolescents 


\section{Introduction}

Child sexual abuse (CSA) has been related to psychiatric, neuroanatomical and cognitive consequences [1]. Child abuse survivors often present psychopathology, including post-traumatic stress disorder (PTSD) [2] [3], as well as lower volumes in some brain areas, particularly the dorsolateral prefrontal cortex [4] [5], the anterior cingulate cortex [5] [6], the corpus callosum [4], and the hippocampus [7].

Neuroimaging studies have shown that CSA survivors can present functional brain alterations in anterior prefrontal cortex, anterior cingulated [8] and other cortical areas. CSA survivors can also manifest changes in brain functional synchronization or connectivity, which can be assessed by EEG coherence (coh) and correlation (r) analyses [9] [10]. Both analyses evaluate the degree of similarity between two EEG signals, though they use distinct mathematical calculations [11]. Sexually-abused women, in particular, show an increase in left intrahemispheric coherence [12], and a decrease in frontal interhemispheric coherence while at rest [13] which could suggest abnormal functional brain connectivity [13].

On the other hand, some studies have reported cognitive deficits in people with diagnoses of CSA and PTSD, finding poor performance in attention, and in abstract reasoning/executive function [14], as well as increased cognitive interference on a color-word Stroop task [15]. Other research has focused on abused subjects regardless of PTSD condition. For example, female victims of repeated CSA showed increased response latency variability and diminished inhibitory capacity during a go/no-go/stop vigilance task designed to assess motor inhibition [16].

The aforementioned research supports the presence of vulnerability to executive function problems in adolescents exposed to CSA, particularly in the development of cognitive flexibility (i.e., the ability to change behavior according to contingencies in the environment). Cognitive flexibility is related to the activation of brain structures such as the dorsolateral prefrontal cortex and cingulate cortex [17], areas that are reported to be affected in CSA. Although there were no previous studies of cognitive flexibility in CSA adolescents, in their work on adolescents without psychiatric disorders, Spann et al. [18] found a significant association between physical abuse and physical neglect scores, and perseverative errors on the Wisconsin Card-Sorting Test (WCST). This test assesses several cognitive functions related to the prefrontal cortex, such as flexibility and categorization [19]-[21].

Considering that CSA has been associated with anatomical and functional alterations in the brain, and cognitive impairments, the aim of the present study was to evaluate EEG correlations in female adolescents with CSA-related PTSD during performance of the WSCT and while at rest. In addition, behavioral performance on the WCST by PTSD subjects will be characterized. We hypothesized that adolescents with CSA-related PTSD would present deficient performance on the WCST compared with the control group, and that this performance would be accompanied by a decrease in frontal interhemispheric EEG correlations.

\section{Method}

\subsection{Participants}

Seven 12 - 16-year old female adolescents with sexual abuse-related PTSD (PTSD), and seven 12 - 16-year old healthy female adolescents (controls), were evaluated (Table 1). Four of the PTSD participants came from foster homes and 3 were external patients at the Civil Hospital of Guadalajara. PTSD participants presented histories

Table 1. Characteristics of the PTSD and control groups.

\begin{tabular}{|c|c|c|c|c|c|}
\hline \multirow[t]{2}{*}{ Characteristics } & \multicolumn{2}{|c|}{ PTSD group } & \multicolumn{2}{|c|}{ Control group } & \multirow{2}{*}{$\begin{array}{c}\text { Comparisons } \\
\mathrm{p}\end{array}$} \\
\hline & M & SE & M & SE & \\
\hline Age (years) & 13.85 & $(0.369)$ & 13.42 & $(0.43)$ & 0.924 \\
\hline IQ & 93.57 & (4) & 94.85 & $(2.9)$ & 0.217 \\
\hline Age of onset of sexual abuse & 7.71 & $(0.83)$ & & & \\
\hline Children’s depression inventory & 55 & $(8.64)$ & 15 & $(8.04)$ & 0.045 \\
\hline Trait anxiety inventory for children & 38.43 & $(3.28)$ & 32.14 & $(1.97)$ & 0.298 \\
\hline
\end{tabular}

Column four presents the significance (p) of the t tests conducted to compare the group values for each variable. 
of CSA (rapes) confirmed by reviewing files held at the institutions concerned (hospital or foster home). The control group was recruited from a public high school. All participants had normal IQs according to the brief form of WISC-IV-R, (Wechsler, 1974) [22] (Table 1), and were regular students with no reports of behavioral problems. They had not failed any school grade, according to reports by teachers and parents. All participants were healthy, right-handed, and had no prior history of neurological disorders, learning disabilities, drug abuse or chronic illness. Subjects in the control group were matched with those in the PTSD group with respect to age, gender, handedness, socioeconomic status, and IQ scores.

To select participants, we conducted a clinical interview with each girl and her parents or advisors, and applied the following clinical scales: the Children's Depression Inventory (CDI) [23], on which two of the participants in PTSD obtained clinically significant scores; the Trait Anxiety Inventory for Children (STAIC) [24], on which five of the participants in PTSD and one in the control group obtained significant scores; and the Children's Post-Traumatic Stress Scale (CPSS) [25], using the criteria listed in the DSM-IV [26], in which all subjects in the PTSD group obtained significantly high scores, while the participants in the control group obtained null scores and showed no history of involvement with traumatic experiences (Table 1). The only significant between-group difference occurred on the CDI, where the PTSD group obtained higher scores than controls.

The evaluations of the participants were conducted from January 2012 to April 2013.

All procedures involved in this experiment were approved by the Ethics Committee of the Institute of Neuroscience in accordance with the ethical standards laid down in the 1964 Helsinki Declaration. All participants and their parents or guardians gave their informed consent prior to their inclusion in the present study.

\subsection{WCST Application}

A computerized version of the WCST [21] was used in this study. In this program, 4 key cards and 128 response cards appear on a computer touch screen. As the response cards appear one-by-one, the participant has to choose one of the four key cards shown to match the response letter. Following each response, the experimenter uses the computer's auditory and visual feedback to indicate whether the answer was correct or incorrect. The application time is approximately 15 - 20 minutes. In this study, we evaluated the following WCST scores: number of categories completed (the number of sequences with 10 consecutive correct matches), number of correct responses, number of perseverative errors (the number of items in which the participant persists in responding incorrectly to a characteristic stimulus), number of incorrect responses (non-perseverative errors), failure to maintain a set (when a subject makes 5 or more consecutive correct matches but then makes an error before successfully completing the category), and learning to learn (the participant's average change in conceptual efficiency across the successive categories, based on percent error difference scores for each consecutive pair of adjacent categories).

\subsection{EEG Recording}

Before EEG recordings, participants are asked to avoid staying up late the night before the registration, as well as, to make a light meal, avoid coffee, tea, cola or drugs that could affect the nervous system.

EEGs recordings were taken with the participants awake in a shielded, dimly-lit room, in a sitting position with their heads supported by the back of a comfortable chair, in two conditions: eyes open at rest (5 min) (resting condition), and during performance of the WCST (maximum time, $15 \mathrm{~min}$ ). Total session time was approximately 1 hour. The recording sites were Fp1, Fp2, F3, F4, P3 and P4, according to the 10 - 20 International System. All derivations were referred to linked ears, the ground electrode was placed on the forehead, and linked ears were chosen as reference. EEGs were amplified using a Grass model P7 polygraph with EEG filters set at 1 - $50 \mathrm{~Hz}$. Impedance for the EEG electrodes was kept below $10 \mathrm{kV}$. Specially-designed software [27] was used to sample (1024 points at a sample rate of $512 \mathrm{~Hz}$ ) and store the EEG data for off-line processing. In addition, electrooculograms were recorded to detect eye-movement artifacts using a bipolar montage with electrodes placed at the outer canthi of both eyes. Epoch rejection was based on both visual and computer selection. In order to identify saturated epochs or epochs with noise due to muscle activity, eye-movement or heart activity, the EEG signals were examined off-line. The recordings were then reduced to a minimum of 40 epochs (2 seconds each) that were representative of the entire time of EEG recording. EEGs were analyzed by a computer program [28] that initially calculates the Fast Fourier Transform (FFT) to seven frequency bands: delta $(1.5-3.5 \mathrm{~Hz})$, theta $(3.5$ - $7.5 \mathrm{~Hz})$, alpha1 (7.5 - 10.5 Hz), alpha2 (10.5 - 13.5 Hz), beta1 (13.5 - $19.5 \mathrm{~Hz})$, beta2 (19.5 - $30 \mathrm{~Hz})$, 
and gamma (30 - $50 \mathrm{~Hz})$. Later, the correlation spectrum was calculated from the autospectra and from the cross-spectrum of the signals proportioning values between -1 and +1 . Correlation spectra at 0 delay for each subject and condition were obtained for each frequency band using amplitude values by means of Pearson product-moment coefficients such that interhemispheric correlations (INTERr) between homologous left and right derivations (Fp1-Fp2, F3-F4, P3-P4), and intrahemispheric correlations (INTRAr) between derivations of the same hemisphere (Fp1-F3, Fp2-F4, Fp1-P3, Fp2-P4, F3-P3, F4-P4), were obtained. Correlation values were transformed to Fisher's z scores to approximate them to a normal distribution before all statistical procedures.

\subsection{Statistical Analysis}

To test the differences between groups on WCST performance, Student's t analyses for independent groups were performed for each execution parameter (raw scores). For the EEG analyses, split-plot ANOVAs (2 groups $\times 2$ conditions) were conducted for EEG correlations of each frequency band and for each pair of derivations. Post-hoc comparisons (Tukey’s test) were utilized to determine where differences occurred $(p<0.05)$.

\section{Results}

\subsection{WCST Performance}

Significant between-group differences were obtained only on two WCST scores: number of correct responses (p $\leq 0.05$ ), where the PTSD group had higher scores than the control group (Figure 1), and failure to maintain set $(\mathrm{p} \leq 0.05$ ), where the PTSD group achieved higher scores than controls (Figure 1). There were no significant between-group differences on the remaining WCST measures.

\subsection{EEG Correlation Data}

1) Between-group comparisons

The frontopolar INTERr (Fp1-Fp2) of the PTSD group presented a higher correlation than the control group during execution of WCST only in the gamma band $\left(F_{1,12}=5.13\right.$, $\left.p<0.0409\right)$ (Figure 2(a)). Also, in the prefrontal INTERr (F3-F4), the PTSD group presented a higher correlation than controls in the delta band in both the resting and WCST conditions $\left(\mathrm{F}_{1,12}=8.71, \mathrm{p}<0.01174\right)$, and in theta band, but only in the resting condition $\left(\mathrm{F}_{1,12}=4.52, \mathrm{p}<0.05\right)$ (Figure 2(b)).

The left frontopolar-prefrontal INTRAr (Fp1-F3) of the PTSD group presented a higher correlation than in the control group in the delta band $\left(\mathrm{F}_{1,12}=7.17, \mathrm{p}<0.01924\right)$ in both the resting and WCST conditions (Figure 2(c)).

In contrast, the left frontopolar-parietal INTRAr (Fp1-P3) of PTSD presented a lower correlation with respect to controls in the theta band $\left(\mathrm{F}_{1,12}=13.39, \mathrm{p}<0.00351\right)$ in both the basal and WCST conditions, as well as in alpha1 $\left(\mathrm{F}_{1,12}=4.28, \mathrm{p}<0.05000\right)$, but only during the WCST (Figure 2(d)). Additionally, the right frontopolarparietal INTRAr (Fp2-P4) of the PTSD group presented a lower correlation than controls in theta $\left(\mathrm{F}_{1,12}=6.75\right.$, $\mathrm{p}$ $<0.02226$ ) in both conditions evaluated (Figure 2(e)).

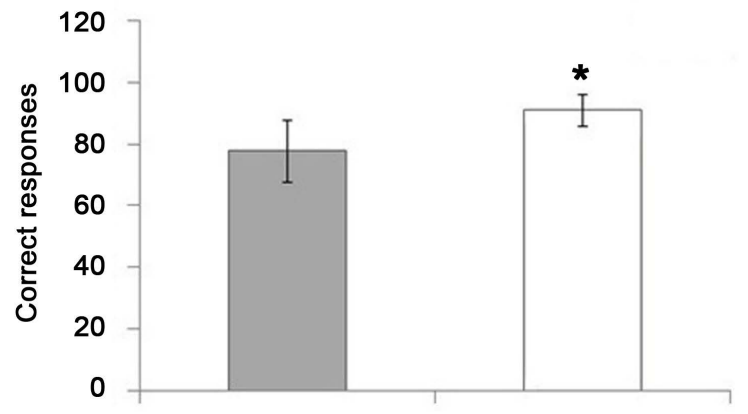

(a)

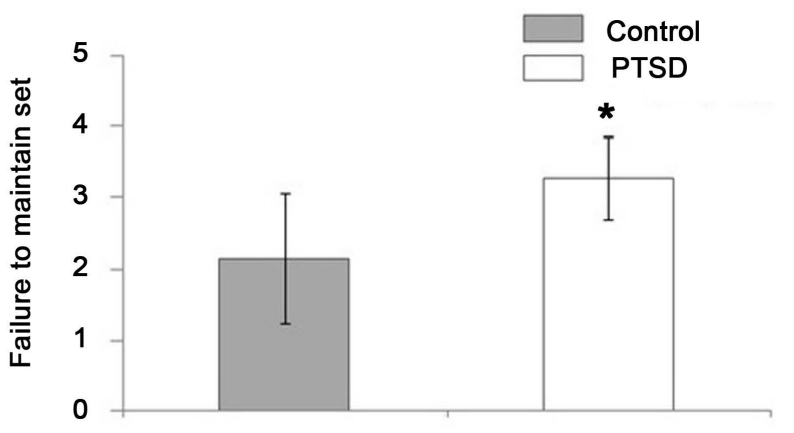

(b)

Figure 1. (a) Mean $( \pm 2 \mathrm{SE})$ of the number of correct responses; (b) Failure to maintain set score for the control and posttraumatic stress disorder (PTSD) groups on the Wisconsin Card-Sorting Test. ${ }^{*} \mathrm{p}<0.05$. 
A

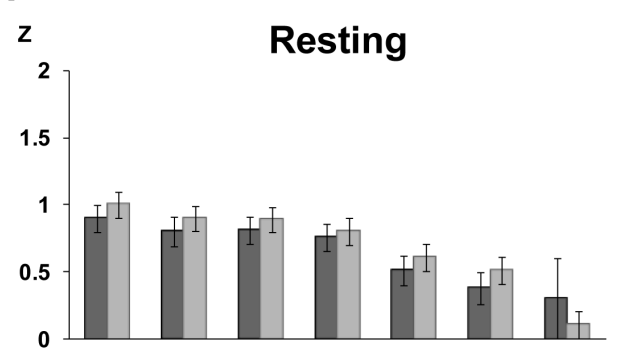

B

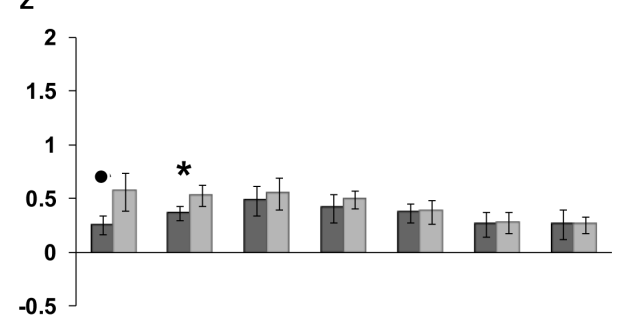

\section{Fp1-Fp2}

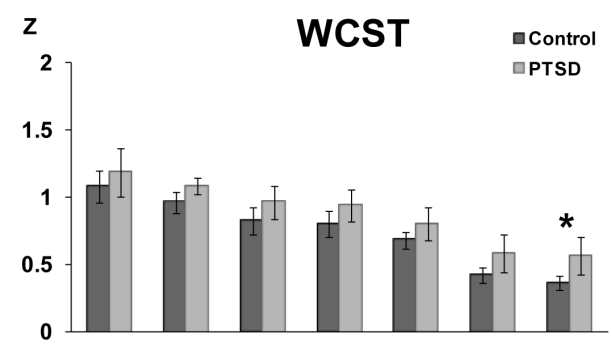

\section{F3-F4}

Z

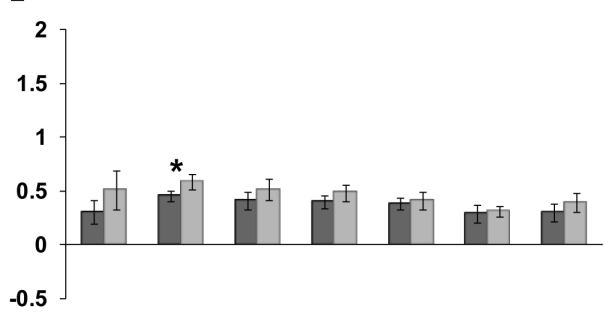

Fp1-F3

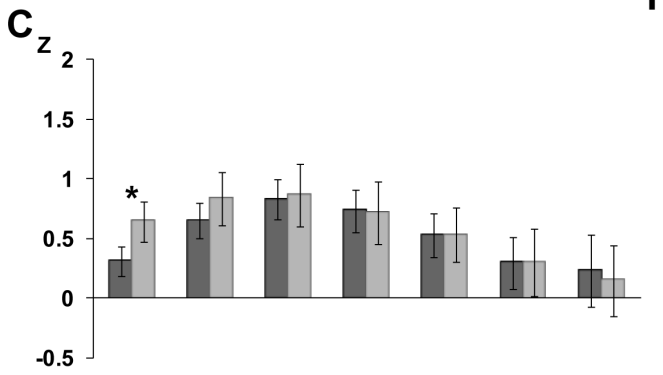

$\mathbf{D}_{\mathbf{Z}}$

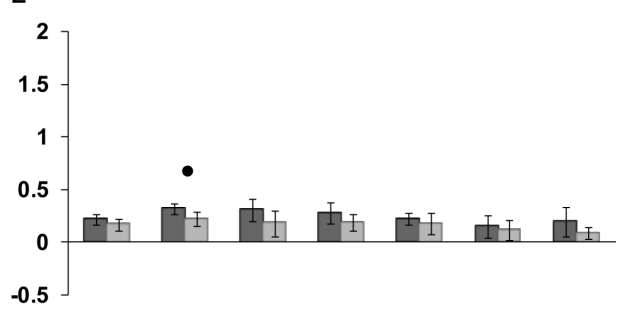

E

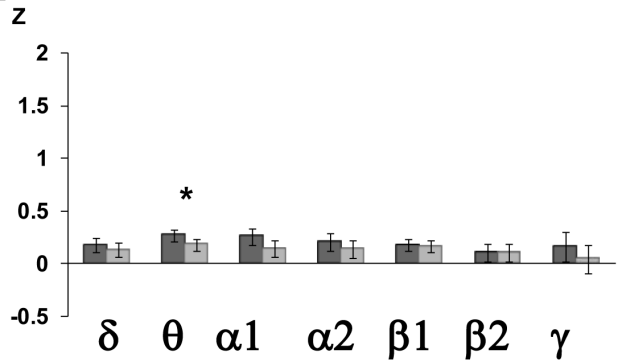

Z

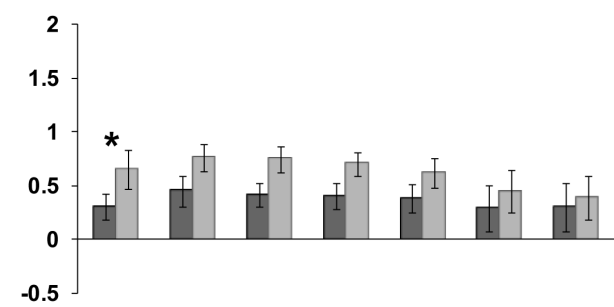

Fp1-P3

Z

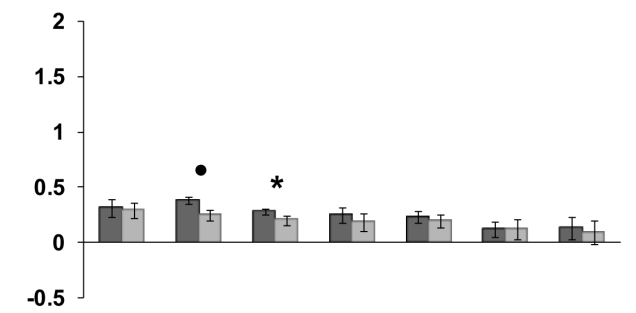

Fp1-P4

$z$

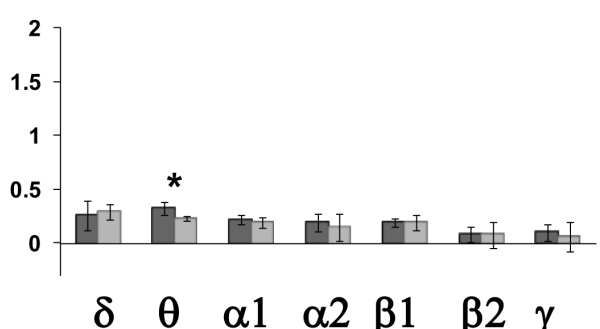

Figure 2. Mean ( $\pm 2 \mathrm{SE}$ ) of the interhemispheric correlation ((a) Fp1-Fp2; (b) F3-F4) and intrahemispheric correlation ((c) Fp1-F3; (e) Fp1-P3 and (f) Fp2-P4) in all bands in the control and post-traumatic stress disorder (PTSD) groups in both the resting and WCST conditions. Significant differences between the control and PTSD groups are indicated with ${ }^{\bullet}(\mathrm{p} \leq 0.01)$ and ${ }^{*}(\mathrm{p}<0.05)$. 
2) Between-conditions comparisons

The frontopolar INTERr (Fp1-Fp2) of the PTSD group presented a significant increase during performance of the WCST compared to the resting condition in the delta $\left(\mathrm{F}_{1,12}=17.68, \mathrm{p}<0.00151\right)$, theta $\left(\mathrm{F}_{1,12}=49.14, \mathrm{p}<\right.$ 0.00007), alpha2 $\left(\mathrm{F}_{1,12}=25.41, \mathrm{p}<0.00049\right)$, beta1 $\left(\mathrm{F}_{1,12}=30.70, \mathrm{p}<0.00027\right)$, beta2 $\left(\mathrm{F}_{1,12}=6.29, \mathrm{p}<\right.$ $0.02622)$, and gamma $\left(\mathrm{F}_{1,12}=11.39, \mathrm{p}<0.00561\right)$ bands. The control group showed a significant increase during execution of the WCST in the delta $\left(\mathrm{F}_{1,12}=17.68, \mathrm{p}<0.00151\right)$, theta $\left(\mathrm{F}_{1,12}=49.14, \mathrm{p}<0.00007\right)$, and beta1 $\left(\mathrm{F}_{1,12}=30.70, \mathrm{p}<0.00027\right)$ bands (Figure 3(a)). The prefrontal INTERr (F3-F4) of PTSD presented a significant increase during performance of the WCST compared only in the gamma band $\left(\mathrm{F}_{1,12}=10.41, \mathrm{p}<0.00724\right)$, while the control group showed this significant difference only in theta $\left(F_{1,12}=17.44, p<0.00157\right)$ (Figure 3(b)).

Regarding the left frontopolar-prefrontal INTRAr (Fp1-F3), only the control group presented a significant decrease in the WCST condition compared to rest in the alpha1 band $\left(\mathrm{F}_{1,12}=7.27, \mathrm{p}<0.01860\right)$ (Figure 3(c)). Similarly, only the right frontopolar-prefrontal INTRAr (Fp2-F4) of the control group showed a significant decrease in the WCST condition in the theta $\left(\mathrm{F}_{1,12}=9.32, \mathrm{p}<0.00982\right)$ and alpha1 $\left(\mathrm{F}_{1,12}=18.25, \mathrm{p}<0.00137\right)$ bands (Figure 3(d)). With respect to the right frontopolar-parietal INTRAr (Fp2-P4), both groups presented a significant increase in the WCST condition in the delta band $\left(\mathrm{F}_{1,12}=31.58, \mathrm{p}<0.00025\right)$. In addition, PTSD showed a significant increase in the WCST condition in the theta band, while the control group presented a significant decrease in the WCST condition in the same band $\left(\mathrm{F}_{1,12}=16.55, \mathrm{p}<0.00185\right)$ (Figure 3(e)). The right prefrontal-parietal INTRAr (F4-P4) of the PTSD group presented a significant increase in the WCST condition in the delta $\left(\mathrm{F}_{1,12}=23.29, \mathrm{p}<0.00064\right)$, theta $\left(\mathrm{F}_{1,12}=30.57, \mathrm{p}<0.00027\right)$, beta2 $\left(\mathrm{F}_{1,12}=8.32, \mathrm{p}<0.01326\right)$, and gamma $\left(\mathrm{F}_{1,12}=30.75, \mathrm{p}<0.00027\right)$ bands, while controls had a significant increase in the WCST condition in the theta $\left(\mathrm{F}_{1,12}=30.57, \mathrm{p}<0.00027\right)$ and beta2 $\left(\mathrm{F}_{1,12}=8.32, \mathrm{p}<0.01326\right)$ bands (Figure $3(\mathrm{f})$ ).

\section{Discussion}

This study examined EEG correlations in a group of female adolescents with CSA-related PTSD during performance of the WCST and while at rest, while also evaluating their performance on this task. In general, our results show clear differences between PTSD participants and healthy girls with no antecedents of violence with respect to both INTERr and INTRAr EEG correlations, as well as WCST performance.

1) WCST performance

Contrary to our expectations, performance by the PTSD group was not clearly lower than that of controls, as the former obtained higher scores for number of correct responses and failure to maintain set. No significant differences were observed between the two groups on the other WCST measures. Most authors have proposed that the WCST assesses the ability to shift sets [19] [29] [30], problem-solving/hypothesis-testing, and response maintenance [29].

Specifically, the number of correct responses reflects the subject's ability to discover the correct classification principle based on trial and error and the examiner's feedback, and to choose the correct rule and maintain this sorting principle (or set) across changing stimulus conditions while ignoring other-now irrelevant—stimulus dimensions [31]. According to the results of this study, the PTSD group had a better ability to find the correct classification principle than controls; hence, it is probable that this group presented greater cognitive flexibility. However, the PTSD group also achieved higher scores for failure to maintain set than controls which suggests that the PTSD group shows a failure to commit to a current category, probably due to deficits in the sustained attention required to filter out the distracting stimulus features present in the cards, or to problems in temporally integrating separate events due to a rapid degeneration of the online information presented in the previous trial [32] [33]. Some studies report the occurrence of failure to maintain set in the absence of significant perseveration in patients with single focal medial/orbital frontal lesions [33], and in college students classified as impulsive-aggressive [34]; a behavioral characteristic that maybe related to disturbances in the orbitofrontal cortex [35].

In terms of the relation between our results and those of the aforementioned studies, it is likely that the failure to maintain set in the absence of significant perseveration in the PTSD group is the result of functional-anatomic alterations in the orbitofrontal cortex. This suggestion is supported by studies which have reported that child maltreatment can alter the development of the frontal lobes [4] [5] [36]. 

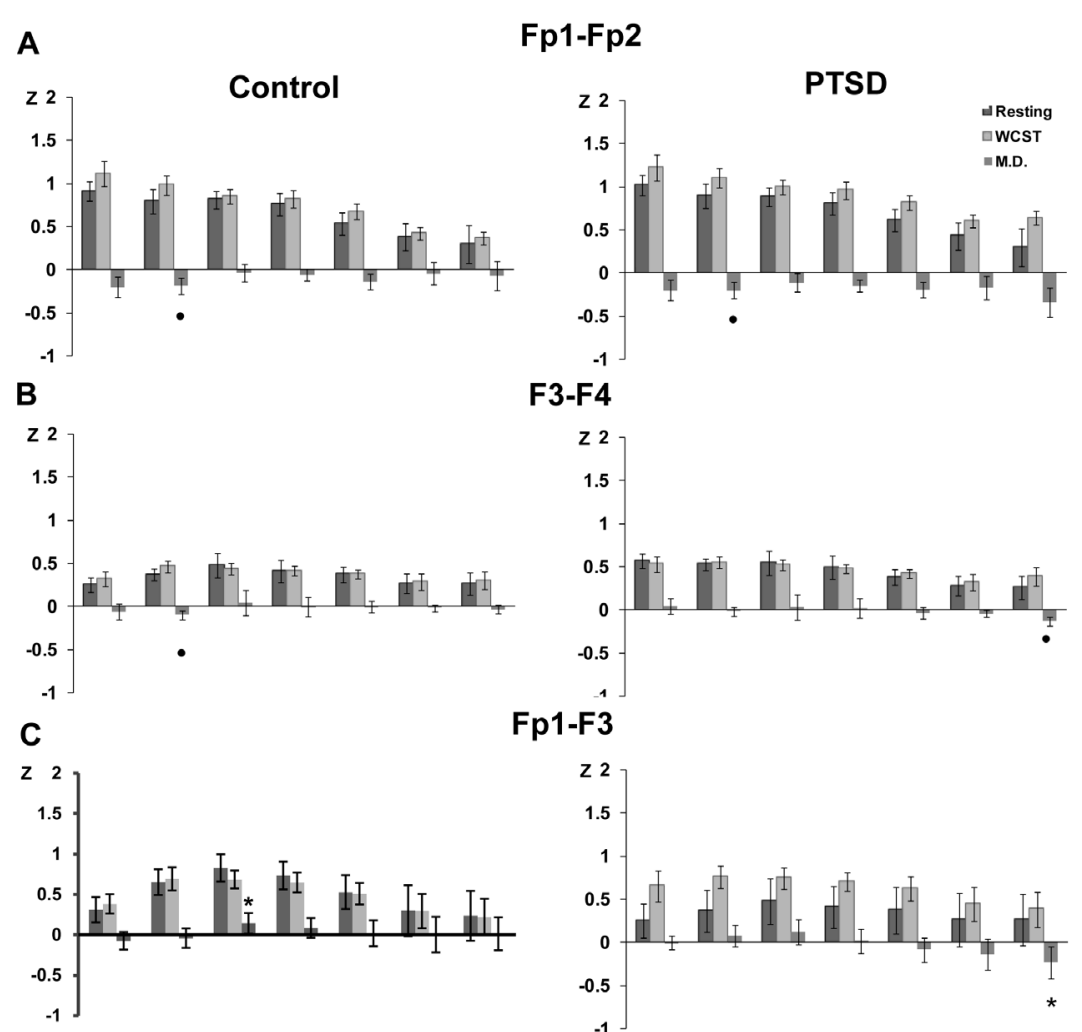

Fp1-F3

D
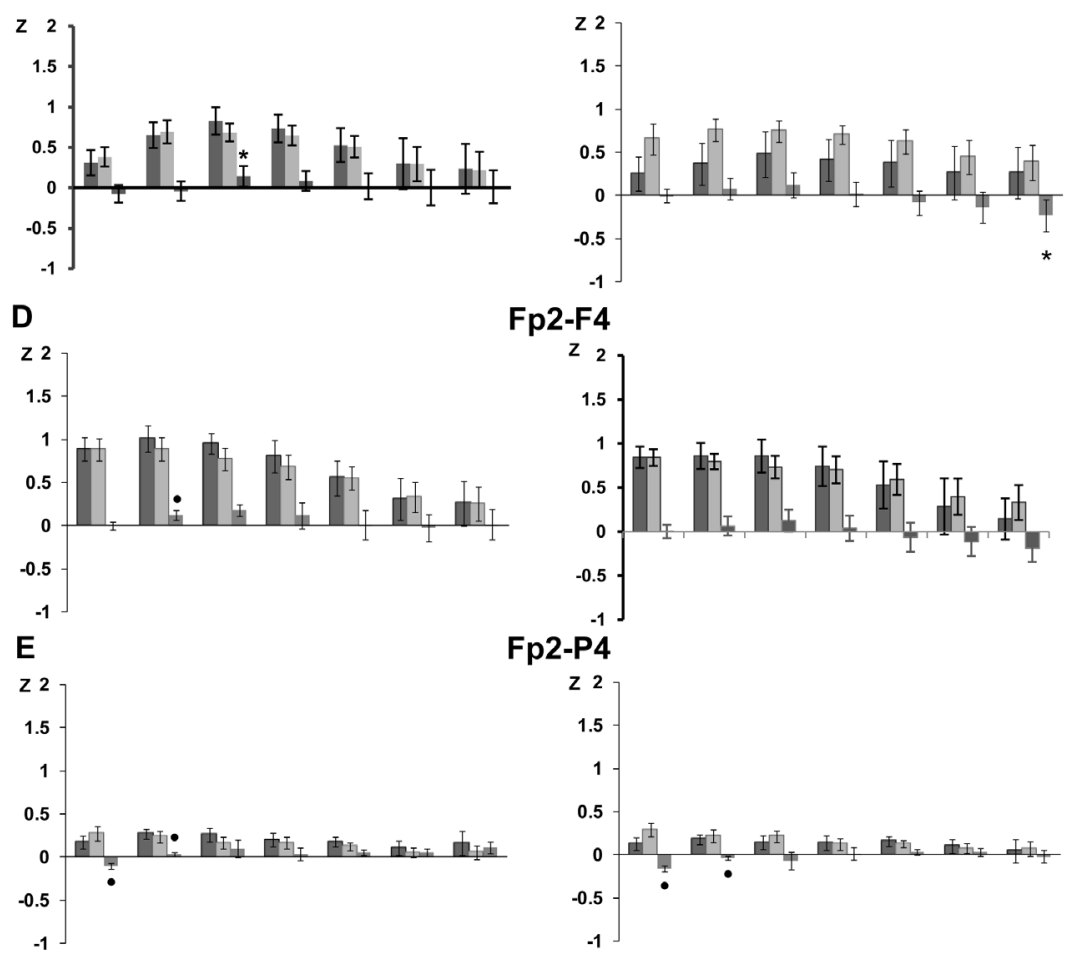

$\mathbf{F}$

p2-F4

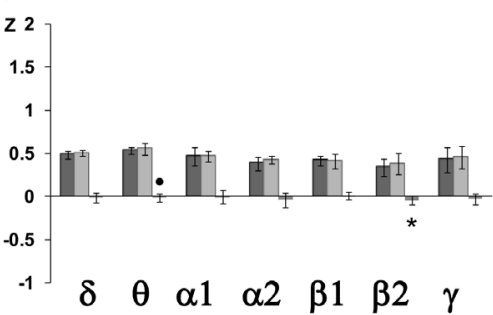

Fp2-P4

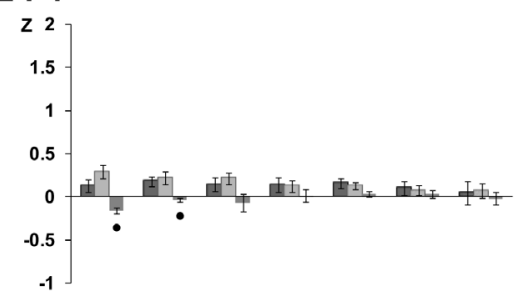

F4-P4

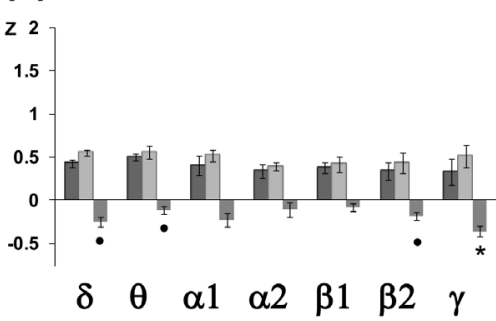

Figure 3. Mean \pm 2SE and mean of differences (MD) of the interhemispheric correlation ((a) Fp1-Fp2; (b) F3-F4) and intrahemispheric correlation ((c) Fp1-F3; (d) Fp2-F4; (e) Fp2-P4; (f) F4-P4) during the resting and WCST conditions in control and post-traumatic stress disorder (PTSD) groups. Significant differences between the resting and WCST conditions are indicated with ${ }^{\bullet}(\mathrm{p} \leq 0.01)$ and ${ }^{*}(\mathrm{p}<0.05)$. 
2) EEG data comparisons between groups

i) INTERr EEG correlation

Contrary to our hypothesis, the PTSD group presented a higher frontal INTERr correlation in Fp1-Fp2 in the gamma band during performance of the WCST, and in F3-F4 in both the basal and WCST conditions in the slow bands. As this correlation increase was found during both conditions, it could reflect a static characteristic of inter-frontal connectivity in this group of female adolescents.

The hypothesis of lower inter-frontal correlation in PTSD individuals was based on two previous findings: the report of reduced frontal (anterior) interhemispheric coherence in adolescents with childhood maltreatment [13], and reports of volume decreases in the corpus callosum in survivors of CA with PTSD [6] [37] and hospitalized children with a history of abuse or neglect [38] [39]. The reduced size of the corpus callosum is associated with a diminished communication between the hemispheres [4] [40].

It is probable that the apparent contradictions between our results and those reported by Miskovic et al. [13] arise from the fact that those authors only analyzed the alpha band, and recorded EEGs only during the resting condition (eyes-open and eyes-closed); whereas our study examined 7 bands under two conditions-while at rest and during performance of the WCST - and found higher inter-frontal correlations in the PTSD group in the delta, theta and gamma bands.

On the other hand, previous studies of changes in the corpus callosum in victims of CA have reported that the reduction in this brain structure occurs in the middle and posterior regions [38], and not in the rostral portion (genu and rostrum) that connect the right and left frontal lobes. While this could explain why we did not find a lower inter-frontal correlation in the PTSD group, it does not explain the higher interhemispheric correlation. We suppose that this might compensate the decrease in the functional connectivity of the posterior regions of the corpus callosum or the lower long-distance intra-hemispheric correlation (discussed below).

A similar increase in inter-frontal coherence in the delta and theta bands has been reported in children with attention deficit disorder (ADD) [10], where it is interpreted as reduced cortical differentiation and specialization in the frontal regions of children with this disorder. Thus, it is probable that the female adolescents with PTSD in our study also show a deficient frontal specialization.

ii) INTRAr EEG correlation

The PTSD group presented a higher correlation at short distances in the left INTRAr frontopolar-prefrontal correlation (Fp1-F3), but a lower correlation at long distances in the left and right INTRAr frontopolar-parietal correlation (Fp1-P3 and Fp2-P4), compared to controls. These results could indicate that brain connectivity in the PTSD group presents a different development from controls, which probably reflects distinct pathways in both the white and gray matter. According to the two-compartment model of EEG coherence proposed by Thatcher, Krause and Hrybyk [41] and Braitenberg [42], our results suggest that the PTSD group presents an increase of short-range connections (local interactions on the order of millimeters to a few centimeters) that occur primarily, but not exclusively, within the grey matter. In contrast, this group of participants could present smaller long-range cortico-cortical connections on the order of several centimeters and composed mostly of white matter fibers. According to Braitenberg [42], these two systems (grey versus white matter) exhibit two different network properties.

The presence of lower long cortico-cortical connectivity in the PTSD group is consistent with tractography and imaging studies. For example, young adults with a history of severe parental verbal abuse show a decrease of white matter density in three tracts: the arcuate fasciculus in the left superior temporal gyre, the cingulum bundle by the posterior tail of the left hippocampus, and the left body of the fornix [43]. Moreover, post-institutionalized children who experienced socio-emotional deprivation show a decreased white matter density in the uncinate fasciculus [44]. Finally, in a recent study, Wang et al. [45] used resting-state functional magnetic resonance imaging to show that major depressive disorder patients with a history of childhood maltreatment displayed a broad reduction of functional connectivity strength primarily in brain regions in the prefrontal-limbicthalamic-cerebellar circuitry.

iii) EEG data comparison between conditions

Upon comparing the resting and task conditions, we found that the PTSD group presented an increase in both frontal INTERr and right INTRAr correlations during performance of the WCST in both slow and fast bands; and that only this group presented a correlation increase in the gamma band. In contrast, the control group presented an increased INTERr correlation principally in the slow bands, with a general decrease in the left and right inter-frontal and fronto-parietal INTRAr correlations in the slow bands (theta, alpha1). 
The results of this study support the hypothesis that the prefrontal cortex is specifically involved in the execution of the WCST, since both the PTSD and control groups presented increased inter-frontal correlation during this condition. A previous EEG-based study reported that inter-frontal coherence is associated with good performance on the WCST [46]. Furthermore, both groups showed an increased right frontal-parietal correlation (F4-P4), which indicates a functional coupling between prefrontal and parietal regions. The posterior parietal areas have reciprocal connections with the frontal regions [47] such that they constitute a circuit that performs the operations necessary to translate an intention into a motion by integrating sensory input into central movement representations based on previous experience.

The changes observed in the INTERr during WCST could be related to many cognitive processes involved in performing this task. For example, the delta band has been related to attention to internal processing during performance of mental tasks [48], and the theta band to working memory, focused attention [49], executive functions [50], and task difficulty [51]. Finally, the beta band has been associated with attention during cognitive processes [52].

Despite the similarities elucidated above, our data suggest that the PTSD and control groups required different temporal coupling during WCST execution. Thus, while the inter-frontal correlation increase in the control group occurred only in the slow bands, in the PTSD group it also occurred in the fast bands. In addition, the PTSD group presented an increase in right frontal-parietal areas in delta, theta, beta2 and gamma, while controls only exhibited this increase in beta2. Also, the control group presented a decrease in the correlation between right frontal areas (Fp2-F4) and between right fronto-polar and parietal (Fp2-P4) regions in the theta and alpha1 bands. In contrast, the PTSD group showed an increase in the right hemisphere in the correlation between right fronto-polar and parietal regions in the slow bands, and between the frontal and parietal regions in both slow and fast bands. This was the only group that presented an increased correlation in gamma.

The gamma and beta bands are generated in the neocortex in response to stimuli of different sensory modalities [53]. The gamma band has also been associated with perceptual binding [54], attention [55], arousal [56], object recognition [57], feature-binding, and associational memory [58] [59]. Finally, gamma oscillations appear during conditions of heightened alertness [60].

Regarding the development of the gamma band, it has been reported that analyses of resting-state and taskrelated neural synchrony indicate that gamma oscillations emerge during early childhood, and that precise temporal coordination through neural synchrony continues to mature until early adulthood [61]. Furthermore, it has been argued that the early gamma band plays a functional role in the maturation of cognitive functions [62].

Considering the above evidence, three possible interpretations of the increase in the gamma band correlation observed in PTSD during WCST execution could be made. The first is that PTSD could have an increased demand for attention and cognitive flexibility during WCST performance, even though it presented deficiencies in maintaining attention (i.e., failure to maintain the set). The second possibility is that this increase could be an intrinsic characteristic of PTSD individuals, since one of the symptoms of PTSD is higher arousal and the appearance of gamma oscillations during conditions of increased alertness. The third likely explanation is that PTSD present early brain maturation as reflected in the higher number of correct responses during WCST performance and the increase in the gamma band during task execution. This idea is supported by studies showing that the gamma band matures into early adulthood and that the early gamma band plays an important role in the functional maturation of cognitive functions [61] [62].

Finally, the present study has some limitations. The first is that, given our strict inclusion criteria, only a small sample of female adolescents with CSA-related PTSD was recruited, so it is difficult to generalize the findings. However, regardless of this limitation, the differences between the two groups were significant. Second, we used EEG correlations, which only allow making inferences related to functional connectivity. Third, in addition to PTSD, two of the PTSD participants had high scores on the depression scale, and five on the anxiety scale. Future studies would be more enlightening if two other groups were evaluated: one with PTSD secondary to a different event of sexual abuse, and one with a history of CSA without PTSD.

\section{Conclusion}

The data from this study suggest that the PTSD group presents a higher level of cognitive flexibility, but deficiencies in maintaining attention, perhaps due to the continuous hyper-vigilance that characterizes this population. In general, PTSD showed higher frontal interhemispheric and left frontal intrahemispheric correlations, as well as a lower fronto-parietal correlation. These results could indicate that this group presents a different de- 
velopment of functional connectivity in the brain. During WCST performance, PTSD showed a significant increase in correlation, principally in the gamma band, perhaps indicating an increase in alertness and an early maturation of synchrony of the gamma band and general cerebral synchrony. These results show that EEG correlations are a useful tool for studying the impact of early stress on functional brain connectivity.

\section{References}

[1] Teicher, M.H., Andersen, S.L., Polcari, A., Anderson, C.M., Navalta, C.P. and Kim, D.M. (2003) The Neurobiological Consequences of Early Stress and Childhood Maltreatment. Neuroscience Biobehavioral Reviews, 27, 33-44. http://dx.doi.org/10.1016/S0149-7634(03)00007-1

[2] Bagley, C. (1992) Characteristics of 60 Children and Adolescents with a History of Sexual Assault against Others: Evidence from a Comparative Study. The Journal of Forensic Psychiatry, 3, 299-309. http://dx.doi.org/10.1080/09585189208407772

[3] Paolucci, E.O., Genuis, M.L. and Violato, C. (2001) A Meta-Analysis of the Published Research on the Effects of Child Sexual Abuse. Journal of Psychology, 135, 17-36. http://dx.doi.org/10.1080/00223980109603677

[4] Andersen, S.L., Tomada, A., Vincow, E.S., Valente, E., Polcari, A. and Teicher, M.H. (2008) Preliminary Evidence for Sensitive Periods in the Effect of Childhood Sexual Abuse on Regional Brain Development. Journal of Neuropsychiatry Clinical Neurosciences, 20, 292-301. http://dx.doi.org/10.1176/jnp.2008.20.3.292

[5] Tomoda, A., Suzuki, H., Rabi, K., Sheu, Y.S., Polcari, A. and Teicher, M.H. (2009) Reduced Prefrontal Cortical Gray Matter Volume in Young Adults Exposed to Harsh Corporal Punishment. NeuroImage, 47, T66-T71. http://dx.doi.org/10.1016/j.neuroimage.2009.03.005

[6] Kitayama, N., Quinn, S. and Bremner, J.D. (2006) Smaller Volume of Anterior Cingulate Cortex in Abuse-Related Posttraumatic Stress Disorder. Journal of Affective Disorders, 90, 171-174. http://dx.doi.org/10.1016/j.jad.2005.11.006

[7] Bremner, J.D., Vythilingam, M., Vermetten, E., Southwick, S.M., McGlashan, T., Nazeer, A., et al. (2003) MRI and Pet Study of Deficits in Hippocampal Structure and Function in Women with Childhood Sexual Abuse and Posttraumatic Stress Disorder. American Journal of Psychiatry, 160, 924-932. http://dx.doi.org/10.1176/appi.ajp.160.5.924

[8] Bremner, J.D., Narayan, M., Staib, L.H., Southwick, S.M., McGlashan, T. and Charney, D.S. (1999) Neural Correlates of Memories of Childhood Sexual Abuse in Women with and without Posttraumatic Stress Disorder. American Journal of Psychiatry, 156, 1787-1795.

[9] Alba, A., Marroquin, J.L., Pena, J., Harmony, T. and Gonzalez-Frankenberger, B. (2007) Exploration of Event-Induced EEG Phase Synchronization Patterns in Cognitive Tasks Using a Time-Frequency-Topography Visualization System. Journal of Neuroscience Methods, 161, 166-182. http://dx.doi.org/10.1016/j.jneumeth.2006.10.018

[10] Murias, M., Swanson, J.M. and Srinivasan, R. (2007) Functional Connectivity of Frontal Cortex in Healthy and ADHD Children Reflected in EEG Coherence. Cereb Cortex, 17, 1788-1799. http://dx.doi.org/10.1093/cercor/bhl089

[11] Shaw, J.C. (1984) Correlation and Coherence Analysis of the EEG: A Selective Tutorial Review. International Journal of Psychophysiology, 1, 255-266. http://dx.doi.org/10.1016/0167-8760(84)90045-X

[12] Ito, Y., Teicher, M.H., Glod, C.A. and Ackerman, E. (1998) Preliminary Evidence for Aberrant Cortical Development in Abused Children: A Quantitative EEG Study. The Journal of Neuropsychiatry Clinical Neurosciences, 10, $298-307$. http://dx.doi.org/10.1176/jnp.10.3.298

[13] Miskovic, V., Schmidt, L.A., Georgiades, K., Boyle, M. and Macmillan, H.L. (2010) Adolescent Females Exposed to Child Maltreatment Exhibit Atypical EEG Coherence and Psychiatric Impairment: Linking Early Adversity, the Brain, and Psychopathology. Development and Psychopathology, 22, 419-432. http://dx.doi.org/10.1017/S0954579410000155

[14] Beers, S.R. and De Bellis, M.D. (2002) Neuropsychological Function in Children with Maltreatment-Related Posttraumatic Stress Disorder. The American Journal of Psychiatry, 159, 483-486. http://dx.doi.org/10.1176/appi.ajp.159.3.483

[15] Freeman, J.B. and Beck, J.G. (2000) Cognitive Interference for Trauma Cues in Sexually Abused Adolescent Girls with Posttraumatic Stress Disorder. Journal of Clinical Child Psychology, 29, 245-256. http://dx.doi.org/10.1207/S15374424jccp2902_10

[16] Navalta, C.P., Polcari, A., Webster, D.M., Boghossian, A. and Teicher, M.H. (2006) Effects of Childhood Sexual Abuse on Neuropsychological and Cognitive Function in College Women. The Journal of Neuropsychiatry Clinical Neurosciences, 18, 45-53. http://dx.doi.org/10.1176/jnp.18.1.45

[17] Jurado, M.B. and Rosselli, M. (2007) The Elusive Nature of Executive Functions: A Review of Our Current Understanding. Neuropsychology Review, 17, 213-233. http://dx.doi.org/10.1007/s11065-007-9040-z

[18] Spann, M.N., Mayes, L.C., Kalmar, J.H., Guiney, J., Womer, F.Y., Pittman, B., et al. (2012) Childhood Abuse and Neglect and Cognitive Flexibility in Adolescents. Child Neuropsychology, 18, 182-189. 
http://dx.doi.org/10.1080/09297049.2011.595400

[19] Barcelo, F. (2001) Does the Wisconsin Card Sorting Test Measure Prefontral Function? The Spanish Journal of Psychology, 4, 79-100. http://dx.doi.org/10.1017/S1138741600005680

[20] Demakis, G.J. (2003) A Meta-Analytic Review of the Sensitivity of the Wisconsin Card Sorting Test to Frontal and Lateralized Frontal Brain Damage. Neuropsychology, 17, 255-264. http://dx.doi.org/10.1037/0894-4105.17.2.255

[21] Heaton, S.K., Chelune, G.J., Talley, J.L., Kay, G.G. and Curtiss, G. (1993) Wisconsin Card Sorting Test Manual: Revised and Expanded. Psychological Assessment Resources, Odessa.

[22] Wechsler, D. (2007) Escala Wechsler de Inteligencia para Niños-IV. Manual Moderno, México.

[23] Kovacs, M. (2004) Inventario de Depresión Infantil (CDI). TEA Ediciones, España.

[24] Spielberg, C.D. (1983) Manual for the State-Trait Anxiety Inventory. Consulting Psychologists Press, Palo Alto.

[25] Bustos, P., Rincón, P. and Aedo, J. (2009) Validación Preliminar de la Escala Infantil de Síntomas del Trastorno de Estrés Postraumático (Child PTSD Symptom Scale, CPSS) en Niños/as y Adolescentes Víctimas de Violencia Sexual. Psykhe (Santiago), 18, 113-126. http://dx.doi.org/10.4067/S0718-22282009000200008

[26] Association, A.P. (1994) Diagnostic and Statistical Manual of Mental Disorders. 4th Edition, American Psychiatric Association, Washington DC.

[27] Guevara, M.A., Ramos, J., Hernández-González, M., Madera, H. and Corsi-Cabrera, M. (2000) Captusen: A System for the Computerized Acquisition of EEG and Event-Related Potentials. Revista Mexicana de Psicología, 171, 77-88.

[28] Guevara, M.A. and Hernández-González, M. (2009) Eegmagic: Programa para analizar señales electroencefalográficas. Revista Mexicana de Ingeniería, 30, 41-53.

[29] Bowden, S.C., Fowler, K.S., Bell, R.C., Whelan, G., Clifford, C.C., Ritter, A.J., et al. (1998) The Reliability and Internal Validity of the Wisconsin Card Sorting Test. Neuropsychological Rehabilitation, 8, 243-254. http://dx.doi.org/10.1080/713755573

[30] Rubinstein, J.S., Meyer, D.E. and Evans, J.E. (2001) Executive Control of Cognitive Processes in Task Switching. The Journal of Experimental Psychology: Human Perception and Performance, 27, 763-797. http://dx.doi.org/10.1037/0096-1523.27.4.763

[31] Nyhus, E. and Barcelo, F. (2009) The Wisconsin Card Sorting Test and the Cognitive Assessment of Prefrontal Executive Functions: A Critical Update. Brain and Cognition, 71, 437-451. http://dx.doi.org/10.1016/j.bandc.2009.03.005

[32] Barcelo, F. and Knight, R.T. (2002) Both Random and Perseverative Errors Underlie WCST Deficits in Prefrontal Patients. Neuropsychologia, 40, 349-356. http://dx.doi.org/10.1016/S0028-3932(01)00110-5

[33] Stuss, D.T., Levine, B., Alexander, M.P., Hong, J., Palumbo, C., Hamer, L., et al. (2000) Wisconsin Card Sorting Test Performance in Patients with Focal Frontal and Posterior Brain Damage: Effects of Lesion Location and Test Structure on Separable Cognitive Processes. Neuropsychologia, 38, 388-402. http://dx.doi.org/10.1016/S0028-3932(99)00093-7

[34] Stanford, M.S., Greve, K.W. and Gerstle, J.E. (1997) Neuropsychological Correlates of Self-Reported Impulsive Aggression in a College Sample. Personality and Individual Differences, 23, 961-965. http://dx.doi.org/10.1016/S0191-8869(97)00120-7

[35] Coccaro, E.F., McCloskey, M.S., Fitzgerald, D.A. and Phan, K.L. (2007) Amygdala and Orbitofrontal Reactivity to Social Threat in Individuals with Impulsive Aggression. Biological Psychiatry, 62, 168-178. http://dx.doi.org/10.1016/j.biopsych.2006.08.024

[36] Hanson, J.L., Chung, M.K., Avants, B.B., Shirtcliff, E.A., Gee, J.C., Davidson, R.J., et al. (2010) Early Stress Is Associated with Alterations in the Orbitofrontal Cortex: A tensor-Based Morphometry Investigation of Brain Structure and Behavioral Risk. The Journal of Neuroscience, 30, 7466-7472. http://dx.doi.org/10.1523/JNEUROSCI.0859-10.2010

[37] De Bellis, M.D., Keshavan, M.S., Clark, D.B., Casey, B.J., Giedd, J.N., Boring, A.M., et al. (1999) Developmental Traumatology. Part II: Brain Development. Biological Psychiatry, 45, 1271-1284. http://dx.doi.org/10.1016/S0006-3223(99)00045-1

[38] Teicher, M.H., Dumont, N.L., Ito, Y., Vaituzis, C., Giedd, J.N. and Andersen, S.L. (2004) Childhood Neglect Is Associated with Reduced Corpus Callosum Area. Biological Psychiatry, 56, 80-85. http://dx.doi.org/10.1016/j.biopsych.2004.03.016

[39] Teicher, M.H., Ito, Y., Glod, C.A., Andersen, S.L., Dumont, N. and Ackerman, E. (1997) Preliminary Evidence for Abnormal Cortical Development in Physically and Sexually Abused Children Using EEG Coherence and MRI. Annals of the New York Academy of Sciences, 821, 160-175. http://dx.doi.org/10.1111/j.1749-6632.1997.tb48277.x

[40] Yazgan, M.Y., Wexler, B.E., Kinsbourne, M., Peterson, B. and Leckman, J.F. (1995) Functional Significance of Individual Variations in Callosal Area. Neuropsychologia, 33, 769-779. http://dx.doi.org/10.1016/0028-3932(95)00018-X

[41] Thatcher, R.W., Krause, P.J. and Hrybyk, M. (1986) Cortico-Cortical Associations and EEG Coherence: A TwoCompartmental Model. Electroencephalography and Clinical Neurophysiology, 64, 123-143. 
http://dx.doi.org/10.1016/0013-4694(86)90107-0

[42] Braitenberg, V. (1978) Cortical Architectonics: General and Areal. In: Brazier, B. and Petsche, H., Eds., Architectonics of the Cerebral Cortex, Raven, New York, 443-465.

[43] Eluvathingal, T.J., Chugani, H.T., Behen, M.E., Juhasz, C., Muzik, O., Maqbool, M., et al. (2006) Abnormal Brain Connectivity in Children after Early Severe Socioemotional Deprivation: A Diffusion Tensor Imaging Study. Pediatrics, 117, 2093-2100. http://dx.doi.org/10.1542/peds.2005-1727

[44] Choi, J., Jeong, B., Rohan, M.L., Polcari, A.M. and Teicher, M.H. (2009) Preliminary Evidence for White Matter Tract Abnormalities in Young Adults Exposed to Parental Verbal Abuse. Biological Psychiatry, 65, 227-234. http://dx.doi.org/10.1016/j.biopsych.2008.06.022

[45] Wang, L., Dai, Z., Peng, H., Tan, L., Ding, Y., He, Z., et al. (2014) Overlapping and Segregated Resting-State Functional Connectivity in Patients with Major Depressive Disorder with and without Childhood Neglect. Human Brain Mapping, 35, 1154-1166. http://dx.doi.org/10.1002/hbm.22241

[46] Carrillo-de-la-Pena, M.T. and Garcia-Larrea, L. (2007) Right Frontal Event Related EEG Coherence (ERCoh) Differentiates Good from Bad Performers of the Wisconsin Card Sorting Test (WCST). Neurophysiologie Clinique/Clinical Neurophysiology, 37, 63-75. http://dx.doi.org/10.1016/j.neucli.2007.02.002

[47] Hyvärinen, J. (1982) The Parietal Cortex of Monkey and Man. Springer-Verlag, New York. http://dx.doi.org/10.1007/978-3-642-81860-8

[48] Harmony, T., Fernandez, T., Silva, J., Bernal, J., Diaz-Comas, L., Reyes, A., et al. (1996) EEG Delta Activity: An Indicator of Attention to Internal Processing during Performance of Mental Tasks. International Journal of Psychophysiology, 24, 161-171. http://dx.doi.org/10.1016/S0167-8760(96)00053-0

[49] Anokhin, A.P., Lutzenberger, W. and Birbaumer, N. (1999) Spatiotemporal Organization of Brain Dynamics and Intelligence: An EEG Study in Adolescents. International Journal of Psychophysiology, 33, 259-273. http://dx.doi.org/10.1016/S0167-8760(99)00064-1

[50] Mizuhara, H. and Yamaguchi, Y. (2007) Human Cortical Circuits for Central Executive Function Emerge by Theta Phase Synchronization. Neuroimage, 36, 232-244. http://dx.doi.org/10.1016/j.neuroimage.2007.02.026

[51] Basar, E., Basar-Eroglu, C., Karakas, S. and Schurmann, M. (2001) Gamma, Alpha, Delta, and Theta Oscillations Govern Cognitive Processes. International Journal of Psychophysiology, 39, 241-248. http://dx.doi.org/10.1016/S0167-8760(00)00145-8

[52] Ramos, J., Corsi-Cabrera, M., Guevara, M.A. and Arce, C. (1993) EEG Activity during Cognitive Performance in Women. International Journal of Neuroscience, 69, 185-195. http://dx.doi.org/10.3109/00207459309003329

[53] Roelfsema, P.R., Engel, A.K., Konig, P. and Singer, W. (1997) Visuomotor Integration Is Associated with Zero Time-Lag Synchronization among Cortical Areas. Nature, 385, 157-161. http://dx.doi.org/10.1038/385157a0

[54] Gray, C.M., Konig, P., Engel, A.K. and Singer, W. (1989) Oscillatory Responses in Cat Visual Cortex Exhibit InterColumnar Synchronization Which Reflects Global Stimulus Properties. Nature, 338, 334-337. http://dx.doi.org/10.1038/338334a0

[55] Tiitinen, H., Sinkkonen, J., Reinikainen, K., Alho, K., Lavikainen, J. and Naatanen, R. (1993) Selective Attention Enhances the Auditory 40-hz Transient Response In Humans. Nature, 364, 59-60. http://dx.doi.org/10.1038/364059a0

[56] Strüber, D., Basar-Eroglu, C., Hoff, E. and Stadler, M. (2000) Reversal-Rate Dependent Differences in the EEG Gamma-Band during Multistable Visual Perception. International Journal of Psychophysiology, 38, 243-252. http://dx.doi.org/10.1016/S0167-8760(00)00168-9

[57] Keil, A., Muller, M.M., Ray, W.J., Gruber, T. and Elbert, T. (1999) Human Gamma Band Activity and Perception of a Gestalt. The Journal of Neuroscience, 19, 7152-7161.

[58] Rodriguez, E., George, N., Lachaux, J.P., Martinerie, J., Renault, B. and Varela, F.J. (1999) Perception’s Shadow: Long-Distance Synchronization of Human Brain Activity. Nature, 397, 430-433. http://dx.doi.org/10.1038/17120

[59] Miltner, W.H., Braun, C., Arnold, M., Witte, H. and Taub, E. (1999) Coherence of Gamma-Band EEG Activity as a Basis for Associative Learning. Nature, 397, 434-436. http://dx.doi.org/10.1038/17126

[60] Sheer, D. (1984) Focused Arousal 40-hz EEG and Dysfunction. In: Ebert, T., Ed., Self Regulation of the Brain and Behavior, Springer, Berlin, 64-84. http://dx.doi.org/10.1007/978-3-642-69379-3 6

[61] Uhlhaas, P.J., Roux, F., Rodriguez, E., Rotarska-Jagiela, A. and Singer, W. (2010) Neural Synchrony and the Development of Cortical Networks. Trends in Cognitive Sciences, 14, 72-80. http://dx.doi.org/10.1016/j.tics.2009.12.002

[62] Benasich, A.A., Gou, Z., Choudhury, N. and Harris, K.D. (2008) Early Cognitive and Language Skills Are Linked to Resting Frontal Gamma Power across the First 3 Years. Behavioural Brain Research, 195, 215-222. http://dx.doi.org/10.1016/j.bbr.2008.08.049 